\title{
$\alpha$-Ferrite Suppression during Fiber Laser Welding of Al-Si Coated 22MnB5 Press-Hardened Steel
}

\author{
The effect of welding Al-Si coated 22MnB5 steel through a pure nickel coating on the \\ microstructure and mechanical properties of the weld in the hot-stamped condition
}

\author{
BY M. SHEHRYAR KHAN, A. MACWAN, E. BIRO, AND Y. ZHOU
}

\begin{abstract}
During laser welding of an Al-Si coated 22MnB5 steel to produce tailor-welded blanks, the Al-Si coating mixes into the weld and causes the formation of the lower strength ferrite phase dispersed in an otherwise martensitic matrix. It has been shown that the presence of the ferrite phase is the principal reason for premature failure of hot-stamped laser-welded joints. Currently, the Al-Si coating is removed prior to welding using an intermediate process. This work showed that adding Ni to the fusion zone of laser welded Al-Si coated $22 \mathrm{MnB5}$ steel by welding through a pure $\mathrm{Ni}$ coating of a specified thickness, ferrite formation can be suppressed, whereby improving the weld strength and successfully shifting failure from the fusion zone, where it normally occurs, to the base material to achieve $100 \%$ joint strength. This work also showed that laser welding Al-Si coated $22 \mathrm{MnB5}$ steel through a Ni coating eliminated the need to mechanically or chemically remove the Al-Si coating prior to welding.
\end{abstract}

\section{KEYWORDS}

- Fiber Laser Welding • Ferrite Suppression

- Tailor-Welded Blanks • Nickel Coating

- Al-Si Coated 22MnB5 - Press-Hardened Steel

- Martensite - Advanced High-Strength Steel

\section{Introduction}

The 22MnB5 press-hardened steel (PHS), sometimes known as hot-stamped (HS) steel, is a boron-alloyed ultrahigh strength steel (UHSS), which has the unique characteristic of having an ultimate tensile strength (UTS) of about $600 \mathrm{MPa}$ in the as-received condition but has a fully martensitic microstructure post hot stamping, increasing the UTS to more than $1550 \mathrm{MPa}$ (Ref. 12). Several automotive components such as the A- and B-pillar, bumper, rocker and roof rail, and the tunnel are presently being made from PHS grades. To make the best use of a PHS, PHSs of various strength levels and thicknesses must be joined to produce components with tailored properties (Ref. 11). This is achieved by joining two or more types of sheet metal using laser welding to form a laser-welded blank, also referred to as a tailor-welded blank (TWB). The blank is then HS to form the part with the designed geometry and required properties (Ref. 5). Due to the high temperature that the steel is exposed to during the hot stamping process, it is commonly coated with an $\mathrm{Al}-\mathrm{Si}$ coating to prevent the formation of oxide scale and provide a strong barrier protection against decarburization (Ref. 4).

The presence of the Al-Si coating poses serious problems during the laser welding of the 22MnB5 PHS, which has been reviewed in detail elsewhere (Ref. 6). During laser welding, the laser will melt the Al-Si coating and the molten coating enters the weld pool, alloying with the fusion zone (FZ) (Ref. 7). As Al is a strong ferrite stabilizer, the increase in FZ Al-content stabilizes the high-temperature delta-ferrite ( $\delta$-ferrite) phase, which can be seen by the contraction of the single-phase austenite $(\gamma)$ region and the expansion of the two-phase $(\gamma+\delta)$ region in the Fe-Al phase diagram leading to a FZ microstructure composed of $\delta$-ferrite islands dispersed in a martensitic matrix (Refs. 10,13). The presence of the nonequilibrium $\delta$-ferrite in the FZ after welding leads to failure along the fusion boundary (FB) in the as-received welded (ARW) condition (Refs. 3, 13, 14, 15). The suppression of $\delta$-ferrite can be achieved by adding an austenite stabilizing element to the FZ, which improves the mechanical properties of the weld (Ref. 1). Sun et al. showed that suppression of $\delta$-ferrite could be achieved by inserting an interlayer of $\mathrm{Ni}$ between the faying surfaces that were then laser welded (Ref. 15). However, the study was limited to the hotstamped (HS) then welded condition that is rarely used to produce TWBs due to the presence of the heat-affected zone that forms around the FZ, which causes a degradation of the mechanical properties of the material surrounding the weld due to martensite tempering (Ref. 13).

As TWBs made from PHSs are only used in the HS condition, the evaluation of FZ mechanical properties and weld performance has more practical consequences in the welded then HS condition compared to the ARW condition. Therefore, to make the best use of TWBs made from PHSs, the 

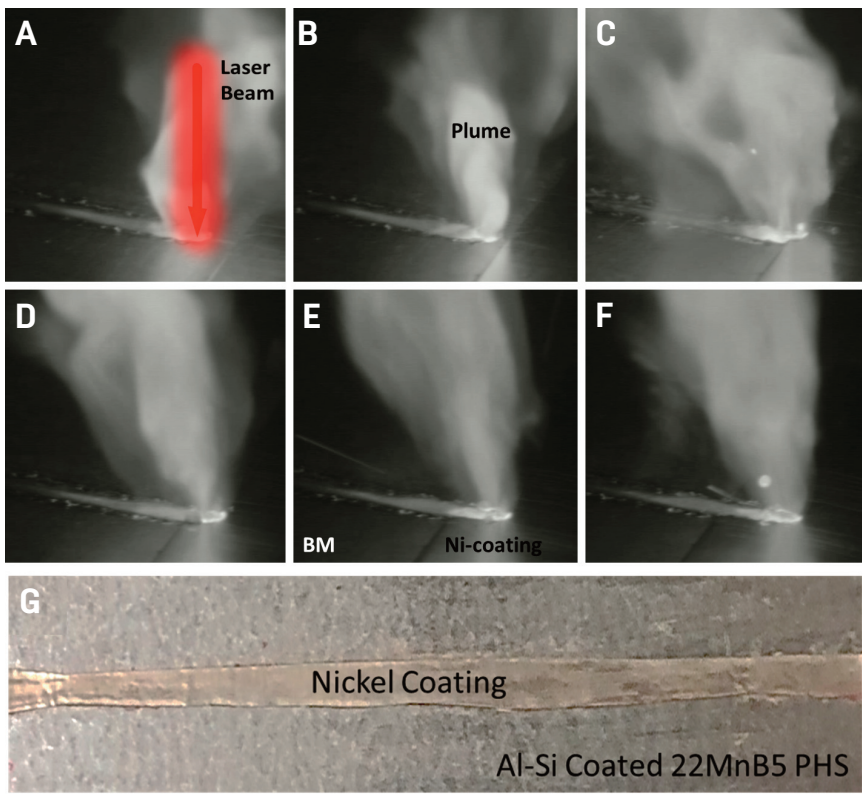

Fig. 1 - Frame-by-frame images of the welding process show the weld being made as the laser traveled from the noncoated substrate $(A, B)$ to the Ni-coated substrate $(C-F)$. The final image (G) shows how the Ni-coating was applied to the Al-Si coated 22MnB5 PHS. The weld was made through the area that is covered by the Ni coating.

steel sheets must first be welded and then HS. This condition is referred to as the as-received-welded then hotstamped (ARWHS) condition. During the hot-stamping process, the material is heated to a temperature of about $930^{\circ}$ to $950^{\circ} \mathrm{C}$ and held for at least $5 \mathrm{~min}$ after which it is quenched in a water-cooled die (Ref. 5). It was shown by Saha et al. that since the material is quenched from a temperature that is between $\mathrm{Ac}_{1}$ and $A c_{3}$, the high temperature nonequilibrium $\delta$-ferrite transforms to the more stable $\alpha$ ferrite phase, which is why a relatively uniform distribution of $\alpha$-ferrite and martensite is obtained in the FZ of the ARWHS condition (Ref. 14). It was also shown by the same author that the ferrite content in the weld increases from about $20 \%$ in the ARW condition to about $40 \%$ in the ARWHS condition, which suggests that even if complete $\delta$-ferrite suppression is achieved in the ARW condition, it is not a guarantee that complete $\alpha$-ferrite suppression will be achieved in the ARWHS condition (Ref. 13). This means that an analysis of mechanical properties must be conducted in the ARWHS condition, which will be the focus of the present work.

The current study investigates the effect of welding an Al-Si coated 22MnB5 steel through a pure nickel coating on the microstructure and mechanical properties of the weld in the HS condition. This condition will be referred to as the welded with $\mathrm{Ni}$ and then hot stamped (WNHS) condition.
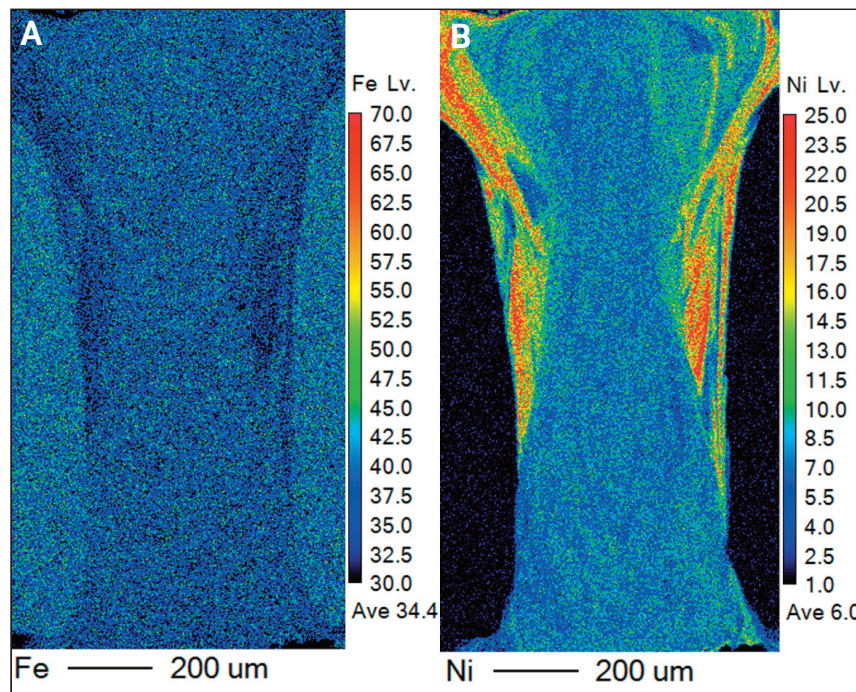

$\mathrm{Fe}-200 \mathrm{um}$

$\mathrm{Ni}-200 \mathrm{um}$

Fig. 2 - EPMA elemental maps: A - Fe; B - Ni showing the dilution of the Ni coating into the FZ for the WNHS condition with the highest concentration of Ni found at the FB, whereas the bulk of the FZ has a more even distribution of Ni content.

The results are compared to the base condition where no nickel coating was used during the welding process. The base condition will be referred to as the ARWHS condition.

\section{Experimental Procedure}

This study was carried out on 1.5-mm-thick Al-Si coated $22 \mathrm{MnB} 5 \mathrm{PHS}$ and the base metal (BM) chemical composition is shown in Table 1. Bead-on-plate (BOP) welds were made on $200 \times 200 \mathrm{~mm}$ sized samples using an IPG Photonics YLS6000 fiber laser mounted to the Panasonic TA1600 six-axis robot. All welds were made perpendicular to the rolling direction of the steel using a laser power of $4 \mathrm{~kW}$ (as shown on the laser controller) and a welding speed of 6 $\mathrm{m} / \mathrm{min}$ with a laser beam diameter of $0.3 \mathrm{~mm}$ and a laser defocus of $6 \mathrm{~mm}$, which has been shown to improve the geometry of the FZ (Ref. 19). Further details about the welding system can be found elsewhere (Ref. 20). A 50- $\mu$ m-thick pure $\mathrm{Ni}$ shim was applied to the area being welded using an adhesive, as shown in Fig. 1G. BOP welds were made through the nickel coating as shown by the still images in Fig. 1A-F captured using the XIRIS XVC1000 welding camera at $90 \mathrm{fps}$. The samples were HS following welding, where they were heated in a furnace for $6 \mathrm{~min}$ to an austenitization temperature of $930^{\circ} \mathrm{C}$ and then quenched using a watercooled die at a cooling rate of approximately $30^{\circ} \mathrm{C} / \mathrm{s}$, which resulted in a fully martensitic microstructure in the asreceived $\mathrm{BM}$ as shown by the high-magnification scanning electron microscope (SEM) images shown in Figs. 5B and 7B.

Table 1-Chemical Composition of the Base Material Used in the Present Work (in wt-\%)

\begin{tabular}{ccccccccccccc} 
Sample Condition & C & Mn & B & Si & Cr & Ti & Mo & P & Ni & Al & Fe \\
\hline BM & 0.23 & 1.22 & 0.0032 & 0.27 & 0.20 & 0.04 & 0.02 & 0.01 & 0.00 & 0.04 & bal. \\
\hline
\end{tabular}


The FZ and BM microstructure were analyzed using the Clemex Vision Lite image analysis software (v. 8.0.197) to measure the phase concentration (PC) of ferrite and martensite in the FZ. To validate the image analysis results, two separately welded samples for each condition were analyzed. Image analysis for the first set of samples was done for the entire FZ, as shown in Fig. 3. For the second set of samples, three regions of interest located at the FB and the center of the FZ were selected, and image analysis was performed at these regions at high magnification to measure the ferrite and martensite PC, as shown in Figs. 4 and 6. The ferrite $P C$ for these regions was averaged and compared to the first set of samples to verify that the image analysis results were accurate. The Zeiss UltraPlus field emission SEM was used to capture high magnification images of the BM, $\mathrm{FB}$, and FZ to clearly identify the different phases.

Elemental analysis to determine the $\mathrm{Al}$ content in the ARWHS condition and the Ni content in the WNHS condition was done using the JEOL JXA-8230 electron probe microanalyzer (EPMA). Hardness was measured using the Clemex CMT (v. 8.0.197) with a 200 gf and a $10 \mathrm{~s}$ dwell time. Hardness maps were constructed using OriginPro. Tensile coupons were first cut from the $200 \times 200 \mathrm{~mm}$ sample using a water jet cutter and then machined to a gauge length of $50 \mathrm{~mm}$ in accordance with ASTM E8/E8M, Standard Test Methods for Tension Testing of Metallic Materials. Each individual tensile coupon was pulled using the Instron 4206 at a speed of $1 \mathrm{~mm} / \mathrm{min}$ and an optical extensometer was used to measure the strain. A total of four tensile coupons were pulled for each condition.

\section{Results and Discussion}

\section{Microstructural Analysis}

EPMA analysis showed that the FZ of the ARWHS sample had an $\mathrm{Al}$ content of $1.02 \mathrm{wt}-\%$ with no traces of $\mathrm{Ni}$ being found (as shown in Table 2). The local Ni content in the FZ of the WNHS condition ranged from about 1.5 to $15 \mathrm{wt}-\%$ and the average bulk Ni content was found to be around 3.5 wt-\% due to the dilution of the Ni-coating into the FZ during the welding process. The cross-sectional area of the FZ was measured at approximately $1.16 \mathrm{~mm}^{2}$ and the crosssectional area of the applied Ni coating was approximately $0.055 \mathrm{~mm}^{2}$, which means theoretically if all of the $\mathrm{Ni}$ coating was to be diluted into the FZ, a bulk Ni content of about $4.74 \mathrm{wt}-\%$ would be expected, which is higher than the measured value of $3.5 \mathrm{wt}-\%$. The low Ni content in the FZ can mainly be attributed to the partial vaporization of the $\mathrm{Ni}$ coating when it encounters the laser beam. The partial vaporization can be confirmed by the increase in the size of the vapor plume as the laser goes from the region of the substrate with no Ni coating (Fig. 1B) to the Ni-coated
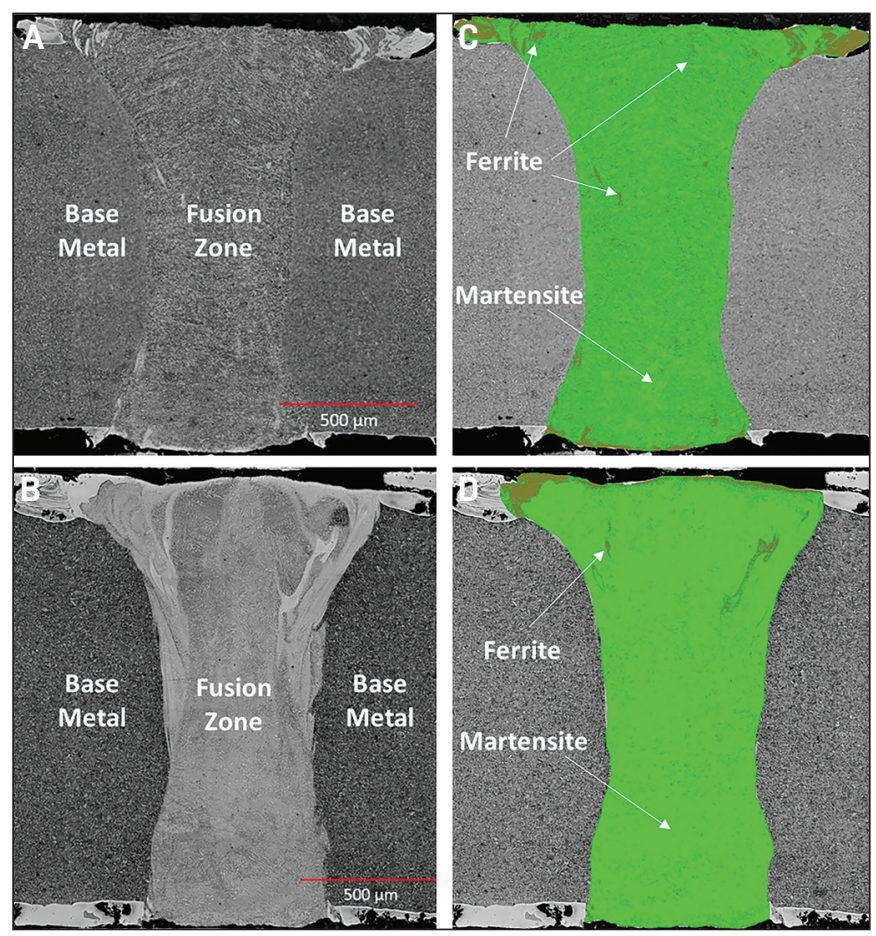

Fig. 3 - Optical micrographs of: A - Weld microstructure with no Ni addition; $B$ - weld microstructure with Ni coating; $C, D$-image analysis using Clemex Vision Lite showing the $P C$ of ferrite (gray color) and martensite (green color) for both conditions, respectively.

region (Fig. 1C). The elemental map for Fe shows that the concentration of $\mathrm{Fe}$ is lower in the $\mathrm{FB}$ where the concentration of $\mathrm{Ni}$ is the highest as shown in Fig. 2A, B, respectively.

Image analysis was used to identify the $P C$ of each phase present in the weld as shown in Fig. 3. When no Ni coating was used, it was found that the FZ had a ferrite PC of $35.4 \%$, shown by the gray phase in Fig. 3C, and a martensite PC of $64.6 \%$, shown by the green phase. These results are similar to those reported in the literature for phase concentrations of the two phases present in the FZ of the ARWHS condition (Refs. 13, 21). Alternatively, when analyzing the weld using the $\mathrm{Ni}$ coating, the ferrite $\mathrm{PC}$ was reduced to $4.2 \%$ with the remainder being made up of martensite as shown in Fig. 3D and these results have been summarized in Table 3 .

To verify the image analysis results shown in Fig. 3 , a second set of identical welds were prepared in the ARWHS and WNHS conditions, and the micrographs of the weld cross sections are shown in Figs. 4A and 6A, respectively. Three regions of interest located at the left-side FB, right-side FB, and the center of the FZ (shown as regions b, c, and d in Figs. 4 and 6) were selected so that the microstructure could be observed at higher magnification and image analysis could be performed

Table 2 - Chemical Composition of the Weld Fusion Zone in the ARWHS and WNHS Conditions (in wt-\%)

\begin{tabular}{ccccccccccccc} 
Sample Condition & $\mathrm{C}$ & $\mathrm{Mn}$ & $\mathrm{B}$ & $\mathrm{Si}$ & $\mathrm{Cr}$ & $\mathrm{Ti}$ & $\mathrm{Mo}$ & $\mathrm{P}$ & $\mathrm{Ni}$ & $\mathrm{Al}$ & $\mathrm{Fe}$ \\
\hline ARWHS & 0.23 & 1.22 & 0.0032 & 0.27 & 0.20 & 0.04 & 0.02 & 0.01 & 0.00 & 1.02 & bal. \\
WNHS & 0.23 & 1.22 & 0.0032 & 0.27 & 0.20 & 0.04 & 0.02 & 0.01 & 3.52 & 1.02 & bal. \\
\hline
\end{tabular}




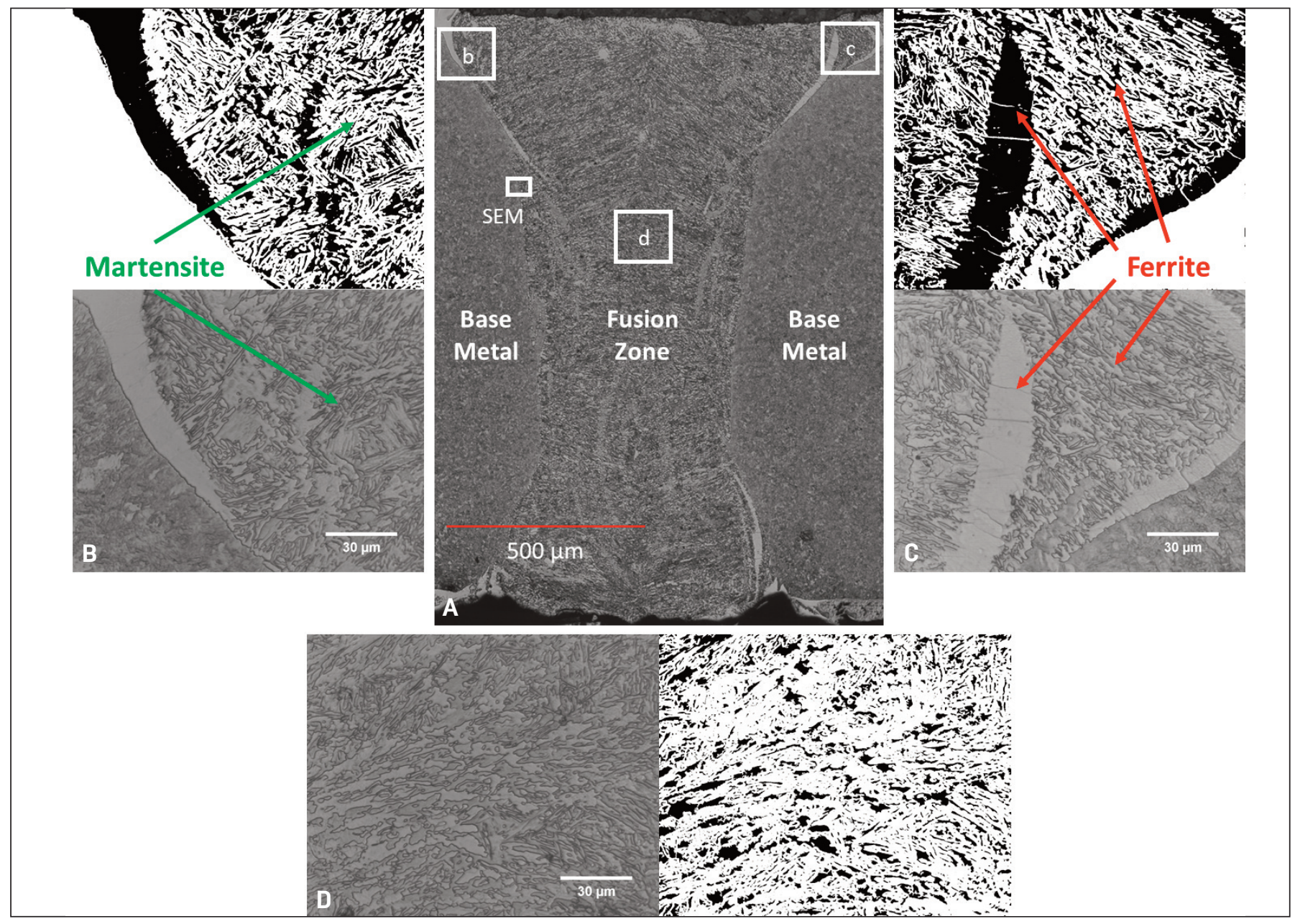

Fig. 4 - Optical micrographs of the: A - Weld microstructure with no Ni addition; B - left-side fusion boundary; $C$ - right-side fusion boundary; $D$ - center of the fusion zone with corresponding images showing the PC of ferrite (black color) and martensite (white color).
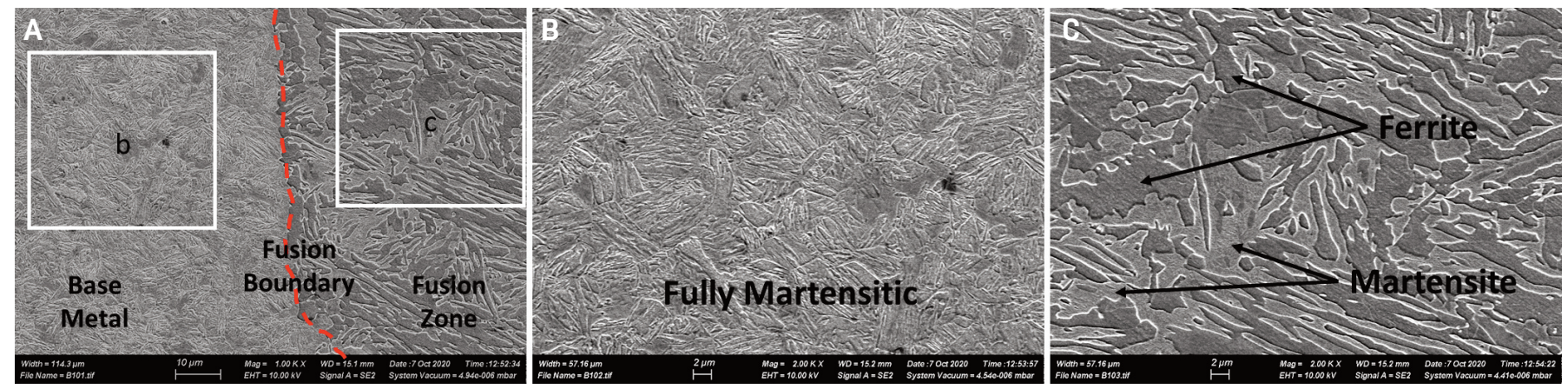

Fig. 5 - SEM images of the: A - Fusion boundary of the ARWHS condition at the location specified in Fig. 4; B - base metal showing a fully martensitic microstructure; $C$ - fusion zone showing the ferrite phase embedded in a martensitic matrix.

for these regions. The measured PC of ferrite for each respective region from the ARWHS and WNHS condition is shown in Table 4. The average ferrite PC for these regions was calculated as 38.1 and $3.0 \%$, respectively, which showed excellent agreement with the image analysis results for the entire FZ as measured for the first set of samples.

High magnification SEM images of the FB region for the ARWHS and WNHS condition are shown in Figs. 5A and 7A, respectively. The SEM images confirm that the BM in both the
ARWHS and WNHS conditions were fully martensitic as shown in Figs. 5B and 7B, respectively. However, the microstructure morphology was significantly different for the FZ in the ARWHS and WNHS condition. The FZ in the ARWHS condition is characterized by the darker ferrite islands embedded in a martensitic matrix as shown in Fig. 5C, which is similar to what has been shown in other studies (Refs. 13, 14). The FZ in the WNHS condition was fully martensitic characterized by prior martensite (PM), which formed at the earlier stages of 


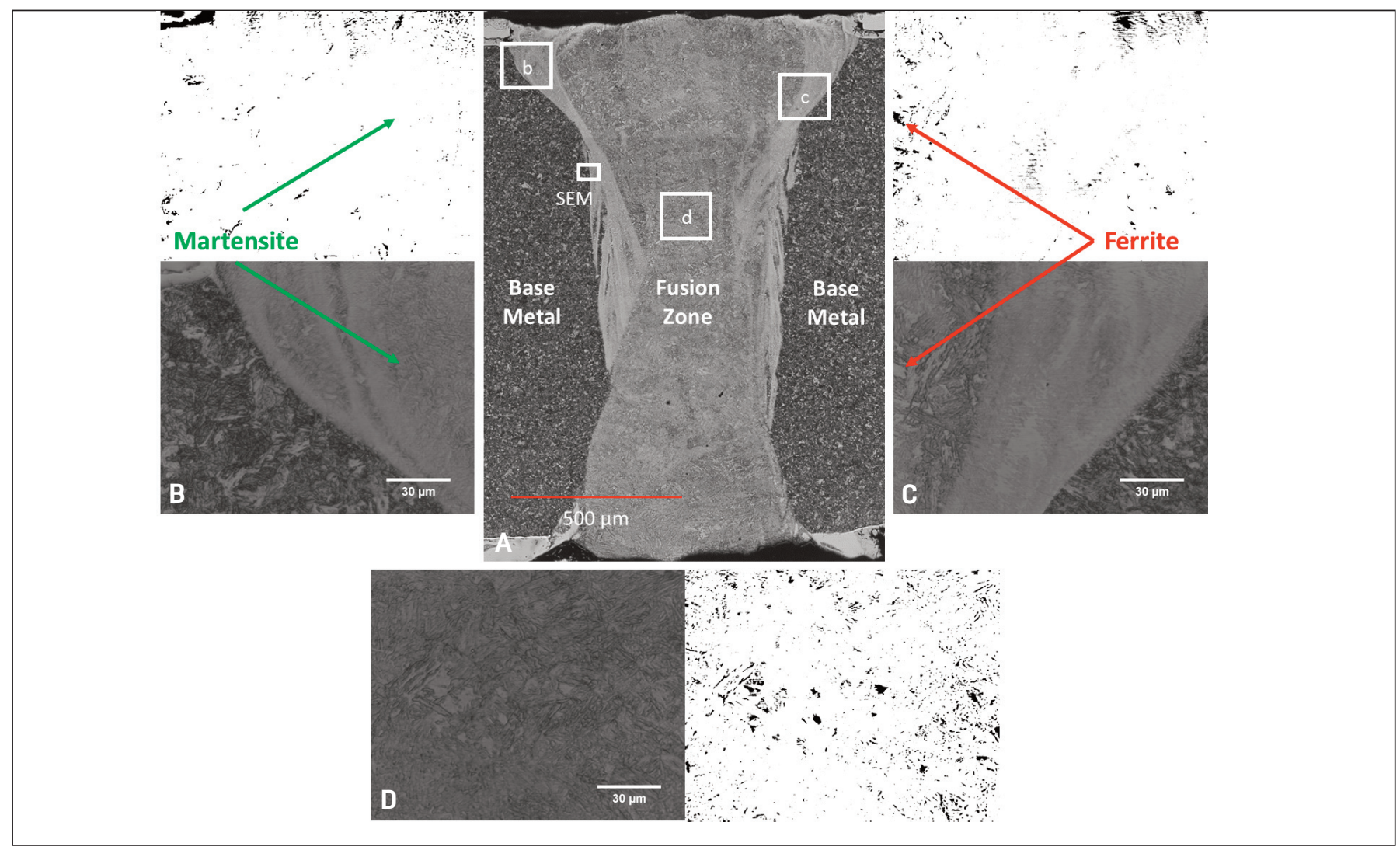

Fig. 6 - Optical micrographs of the: A - Weld microstructure with Ni coating; B - left-side fusion boundary; $C$ - right-side fusion boundary; $D$ - center of the fusion zone with corresponding images showing the $P C$ of ferrite (black color) and martensite (white color).
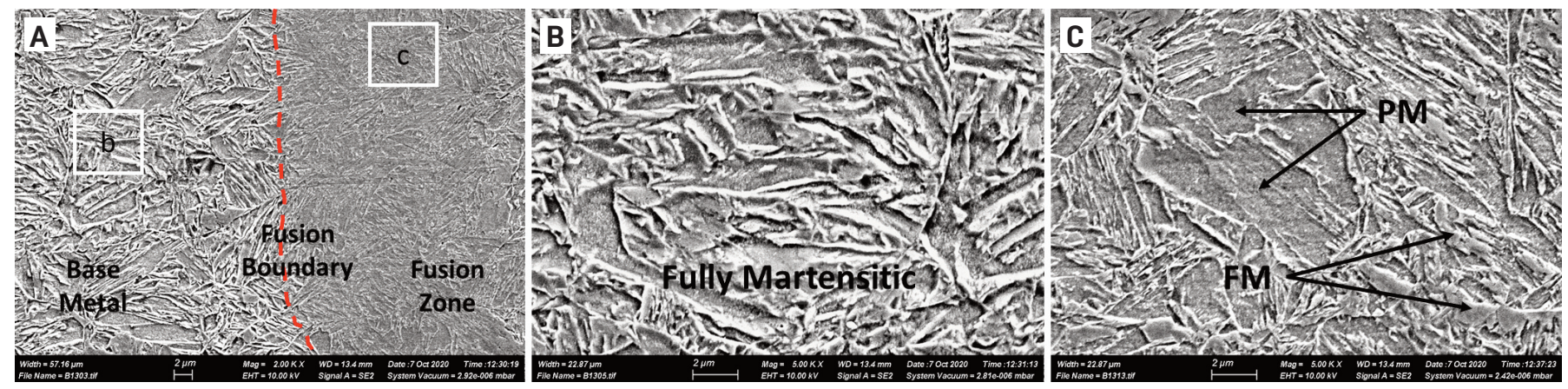

Fig. 7-SEM images of the: A - Fusion boundary of the WNHS condition at the location specified in Fig. 6; B - base metal showing a fully martensitic microstructure; $C$ - martensitic fusion zone showing a combination of prior martensite characterized by the darker concave morphology and fresh martensite characterized by the lighter convex morphology.

Table 3 - Summary of the Ferrite PC Found in the ARWHS and WNHS Conditions

\begin{tabular}{ccc} 
Sample Condition & Ferrite PC & Martensite PC \\
\hline ARWHS & $35.4 \%$ & bal. \\
WNHS & $4.2 \%$ & bal. \\
\hline
\end{tabular}

the quenching process, and fresh martensite (FM), which formed at a later stage during quenching as shown by Fig. 7C. $\mathrm{PM}$ and FM were identified in the microstructure of steels containing Ni by Yao et al. (Ref. 17) who showed that PM had a lower carbon content as it formed at higher temperatures, which gives it better toughness properties compared to FM. Furthermore, they showed that the PM etched easily, was darker, and its microstructural morphology was concave similar to what is shown in Fig. 7C.

Martin et al. confirmed that aluminum is a strong ferrite stabilizer that reduces the size of the single-phase austenite region in the $\mathrm{Fe}-\mathrm{Al}$ phase diagram (Ref. 10). It was clearly seen that the addition of $\mathrm{Ni}$ into the $\mathrm{FZ}$ stabilized the austenite phase by expanding the size of the single-phase austenite region as compared to the size of the single-phase 

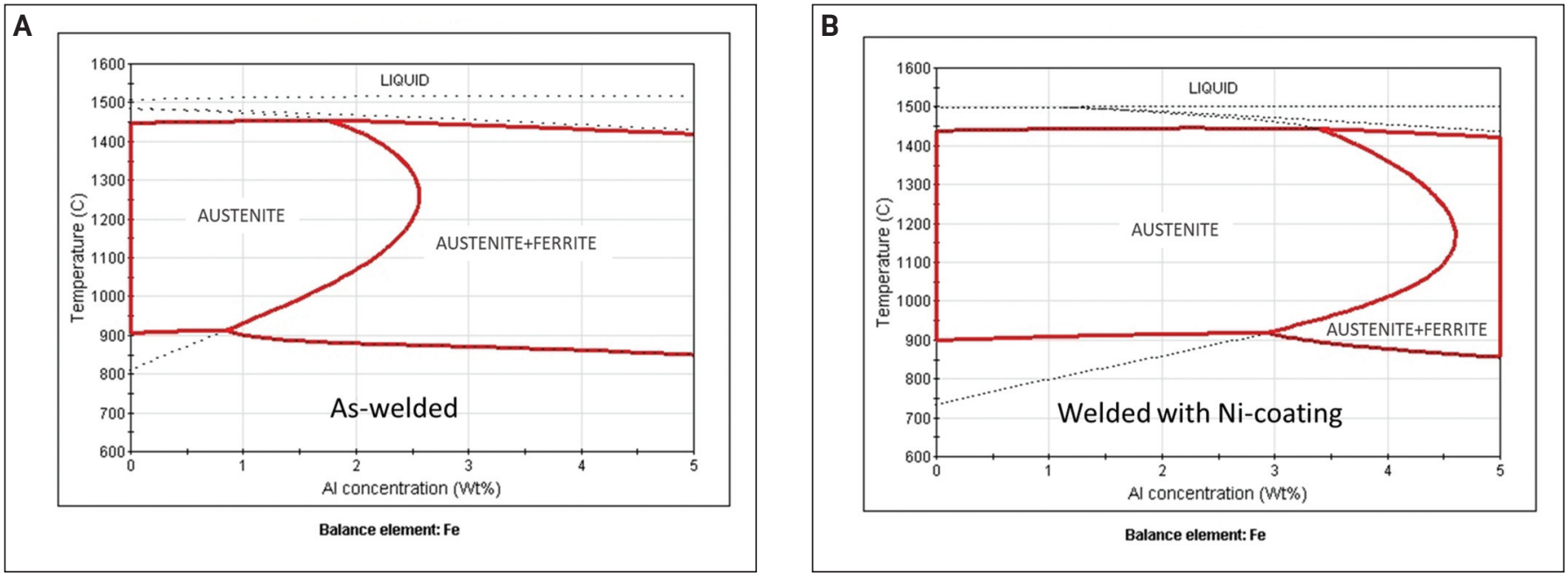

Fig. 8 - Fe-Al phase diagrams generated using JMatPro (v. 11.2) for: A - The ARWHS FZ composition in which there is no Ni, and the arrow is showing that at the austenitization temperature of $930^{\circ} \mathrm{C}$, the $\mathrm{FZ}$ microstructure is composed of austenite and ferrite; $B-$ the WNHS FZ composition showing the addition of Ni stabilizes the single-phase austenite region thereby increasing the PC of the martensite at the end of the hot stamping process, and the arrow is showing that the FZ microstructure at $930^{\circ} \mathrm{C}$ is fully austenitic.
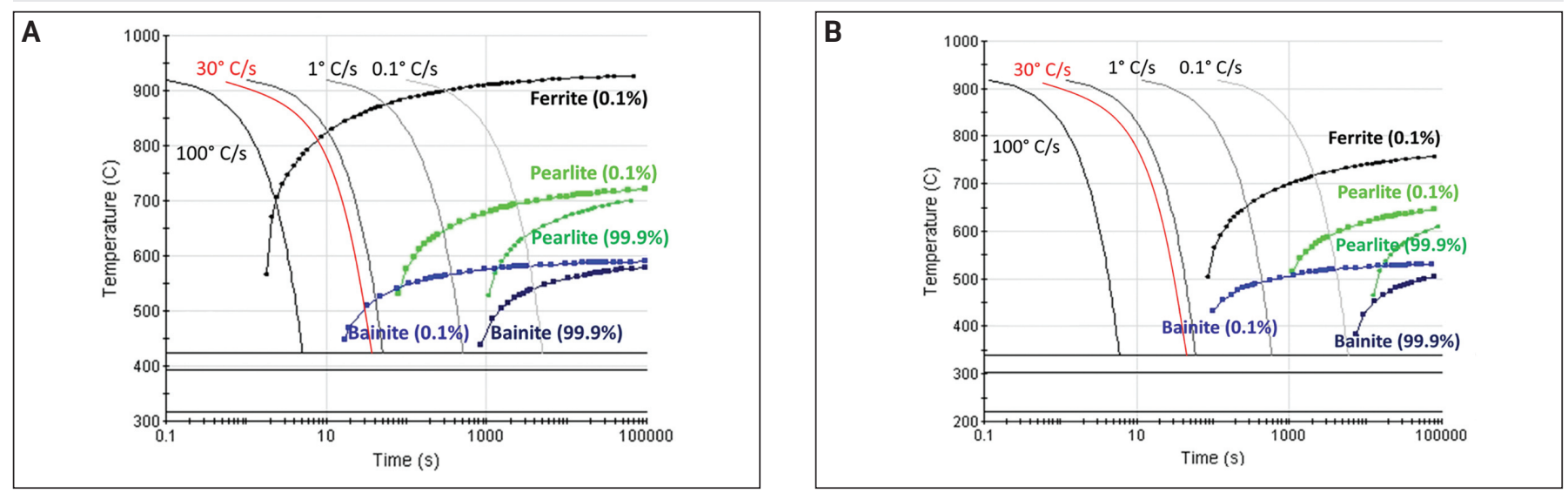

Fig. 9 - Predictive CCT diagrams for: A - ARWHS FZ composition showing that at a $30^{\circ} \mathrm{C} / \mathrm{s}$ cooling rate, the weld microstructure is expected to be a combination of ferrite and martensite; B - WNHS FZ composition showing that the weld microstructure is expected to be purely martensitic at $a 30^{\circ} \mathrm{C} / \mathrm{s}$ cooling rate.

austenite region in the $\mathrm{Fe}-\mathrm{Al}$ phase diagram generated using JMatPro (v. 11.2) for the ARWHS FZ composition as shown in Fig. 8. The increase in the size of the single-phase austenite region ensures that during austenitization at a temperature of $930^{\circ} \mathrm{C}$, the $\mathrm{FZ}$ microstructure was completely austenitic in the welded with $\mathrm{Ni}$ coating condition compared to the dual-phase ferritic and austenitic microstructure observed in the ARW condition, as shown in Fig. 8A. Therefore, it can be said that the addition of $\mathrm{Ni}$ into the FZ stabilizes the austenite phase leading to a direct reduction in $\alpha$ ferrite PC that is observed in the weldment.
CCT curves generated using JMatPro (v. 11.2) predicted that at a cooling rate of about $30^{\circ} \mathrm{C} / \mathrm{s}$, the microstructure of the FZ in the ARWHS condition would be a mixture of ferrite and martensite as shown in Fig. 9A, which agrees with the PC results shown in Tables 3 and 4 . Conversely, the CCT diagram for the FZ of the WNHS condition predicted that the weld should have a fully martensitic microstructure, as shown in Fig. 9B. However, the ferrite PC of the FZ in the WNHS condition was shown to be about 3$4 \%$ with the remainder being made up of martensite. The small disagreement between the ferrite PC observed in the

Table 4-Summary of the Ferrite PC Found in the ARWHS and WNHS Conditions Measured Using Image Analysis for Three Distinct Regions of Interest at High Magnification

\begin{tabular}{lccccc}
$\begin{array}{c}\text { Sample } \\
\text { Condition }\end{array}$ & Ferrite PC & Ferrite PC & \multicolumn{2}{c}{$\begin{array}{c}\text { Ferrite PC } \\
\text { Region d }\end{array}$} & $\begin{array}{c}\text { Average } \\
\text { Ferrite PC }\end{array}$ \\
\hline ARWHS & Region b & Region c & $21.5 \%$ & $38.1 \%$ & bartensite \\
WNHS & $43.3 \%$ & $49.5 \%$ & $4.8 \%$ & $3.0 \%$ & bal. \\
\hline
\end{tabular}



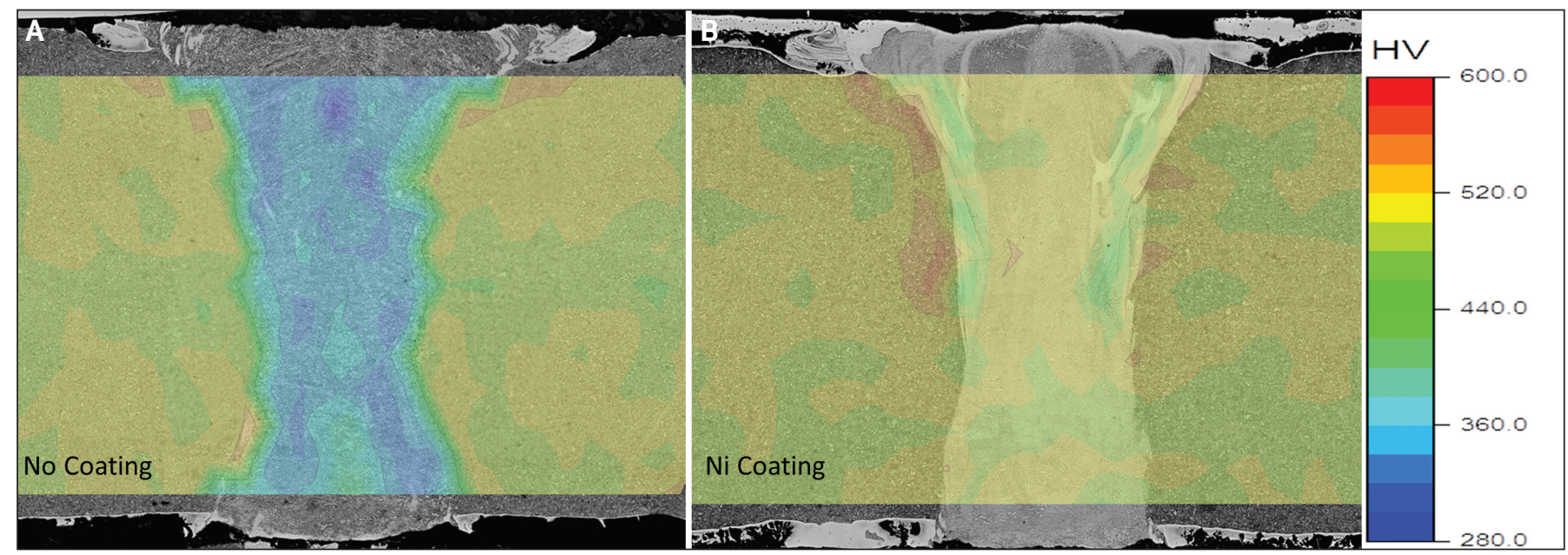

Fig. 10 - Hardness maps for: A - BM and FZ of the ARWHS condition showing a significantly softer FZ as compared to the BM; B $-B M$ and $F Z$ of the WNHS condition showing that the average FZ hardness is the same as that of the BM.

image analysis results and the CCT diagram can be explained by recognizing that the CCT diagram has been generated for a fixed bulk material chemical composition while, in reality, the local chemical composition in certain parts of the FZ may be different than the bulk chemical composition. For this reason, very small amounts of ferrite may still be found in the FZ. The CCT diagrams can be used in conjunction with the Fe-Al phase diagrams to confirm that as the Ni content in the weld increases, the $\alpha$-ferrite $P C$ decreases, leading to an almost fully martensitic microstructure in the FZ upon cooling.

\section{Mechanical Properties}

As the $\alpha$-ferrite content in the weldment significantly lower in the WNHS condition compared to the ARWHS condition as determined by the image analysis, the difference leads to an observable effect on the mechanical properties of the weld. To generate hardness maps as shown in Fig. 10, 299 microhardness indents were made in the BM and FZ of the ARWHS and WNHS conditions. The BM hardness was measured at about $500 \mathrm{HV}$, which falls within the range reported in previous research (Refs. 9, 13, 18). The average FZ hardness for the ARWHS condition was measured at about $350 \mathrm{HV}$, which was significantly lower than the BM hardness as shown in Fig. 10A, which agrees with the data reported in the literature and showed that the difference in hardness was due to the presence of $\alpha$-ferrite (Refs. 13, 21). However, due to the reduced ferrite PC in the FZ of the WNHS condition, the average hardness was measured to be around $500 \mathrm{HV}$, which is the same as the BM hardness.

Due to the high-ferrite PC present in the FZ and the relatively lower hardness, the weld strength in the ARWHS condition was measured at about $1276 \pm 11 \mathrm{MPa}$ and sudden fracture was observed in the FZ, which agrees with the literature (Refs. 3, 8, 9, 13). However, due to the reduction in ferrite $\mathrm{PC}$ and the subsequent improvement in FZ hardness, the UTS for the WNHS condition matched that of the BM at around $1562 \pm 5 \mathrm{MPa}$ and failure in these samples occurred in the BM with the crack propagating on an angle showing the plane of maximum shear stress as shown in Fig. 11.

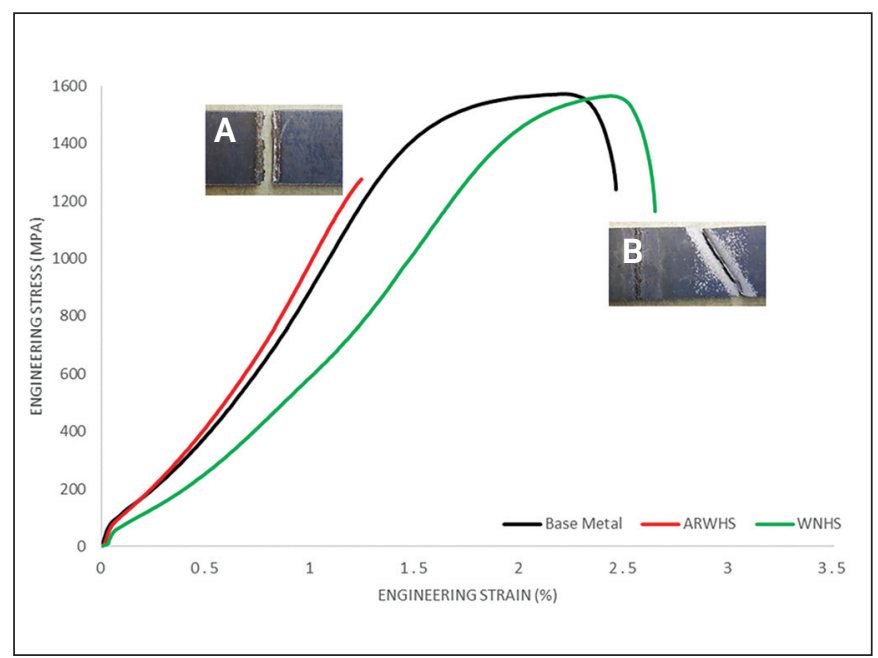

Fig. 11 - Flow curves for the hot-stamped BM, ARWHS condition, and WNHS condition with inserts showing: $A-$ The failure location of the ARWHS samples along the FB due to the high $P C$ of $\alpha$-ferrite present in the FZ; $B-$ the failure location of the WNHS samples in the BM.

\section{Conclusion}

By welding an Al-Si coated 22MnB5 PHS through a pure $\mathrm{Ni}$ coating followed by a hot stamping process, the strength of the welds was increased to that of the hotstamped BM, and the failure location was shifted from the FZ to the BM. Prior to welding, a $50-\mu \mathrm{m} \mathrm{Ni}$ shim was applied using an adhesive to 1.5 -mm-thick $\mathrm{Al}$-Si coated $22 \mathrm{MnB} 5$ steel, and fiber laser welds were then made through the Ni coating. This condition was compared to that in which welds were made with no Ni coating applied as well as the nonwelded BM and all the samples were hot stamped using identical conditions. It was found that by welding Al-Si coated 22MnB5 steel through a Ni coating, the Ni content in the weld can be increased, which suppresses the formation of $\alpha$-ferrite. This improved the hardness and the UTS of the FZ to match that of the BM. 
Therefore, it can be concluded that the aforementioned method can be used to improve the mechanical properties of Al-Si coated TWBs without requiring the removal of the Al-Si coating prior to welding.

\section{Acknowledgments}

This work would not have been possible without the support of the Natural Sciences and Engineering Research Council (NSERC) of Canada and the Canada Research Chairs Program. The authors would also like to acknowledge ArcelorMittal for supporting this project. Special thanks to Dr. Hadi Razmpoosh for his words of guidance and support. Sincere gratitude to Ali Ghatei for helping with the SEM images on short notice in the middle of a pandemic. Disclosure Statement: None. Funding Details: This project was supported with funding from ArcelorMittal and a grant from NSERC Canada (547491-2020).

\section{References}

1. Brandt, M., Both, C., Schaftinger, D., and Hornscheidt, C. 2010. Method for Producing Tailored Sheet Steel Products to be WarmFormed. US20130236239A1.

2. Dosdat, L., Petitjean, J., Vietoris, T., and Clauzeau, O. 2011. Corrosion resistance of different metallic coatings on press-hardened steels for automotive. Steel Research International 82(6): 72633. DOI: $10.1002 /$ srin. 201000291

3. Ehling, W., Cretteur, L., Pic, A., Vierstraete, R., and Yin, Q. 2009. Development of a laser decoating process for fully functional Al-Si coated press hardened steel laser welded blank solutions. Proceedings of the $5^{\text {th }}$ International WLT-Conference on Lasers in Manufacturing. Munich, Germany.

4. Fan, D. W., and De Cooman, B. C. 2012. State-of-the-knowledge on coating systems for hot stamped parts. Steel Research International 83(5): 412-33. DOI: 10.1002/ srin.201100292

5. Karbasian, H., and Tekkaya, A. E. 2010. A review on hot stamping. Journal of Materials Processing Technology 210(15): 210318. DOI: 10.1016/j.jmatprotec.2010.07.019

6. Khan, M. S., Razmpoosh, M. H., Biro, E., and Zhou, Y. 2020. A review on the laser welding of coated 22MnB5 press-hardened steel and its impact on the production of tailor-welded blanks. Science and Technology of Welding and Joining 25(6): 447-67. DOI: 10.1080/13621718.2020.1742472

7. Kim, C., Kang, M. J., and Park, Y. D. 2011. Laser welding of Al-Si coated hot stamping steel. Procedia Engineering 10(1): 222631. DOI: 10.1016/j.proeng.2011.04.368

8. Lin, W., Li, F., Hua, X., and Wu, D. 2018. Effect of filler wire on laser welded blanks of Al-Si-coated 22MnB5 steel. Journal of Materials Processing Technology 259(12): 195-205. DOI: 10.1016/j.jmatprotec.2018.04.041

9. Lin, W., Li, F., Wu, D., Chen, X., Hua, X., and Pan, H. 2018. Effect of Al-Si coating on weld microstructure and properties of 22MnB5 steel joints for hot stamping. Journal of Materials Engi- neering and Performance 27(4): 1825-36. DOI: 10.1007/s11665018-3259-0

10. Martín, D., San, Y., Palizdar, C., García-Mateo, R., Cochrane, C., Brydson, R., and Scott, A. J. 2011. Influence of aluminum alloying and heating rate on austenite formation in low carbon-manganese steels. Metallurgical and Materials Transactions A: Physical Metallurgy and Materials Science 42(9): 2591-2608. DOI: 10.1007/s11661-011-0692-1

11. Merklein, M., Wieland, M., Lechner, M., Bruschi, S., and Ghiotti, A. 2016. Hot stamping of boron steel sheets with tailored properties: A review. Journal of Materials Processing Technology 228: 11-24. DOI: 10.1016/j.jmatprotec.2015.09.023

12. Naderi, M. 2007. Hot stamping of ultra high strength steels. PhD diss., RWTH Aachen University.

13. Saha, D. C., Biro, E., Gerlich, A. P., and Zhou, Y. N. 2016. Fiber laser welding of Al-Si coated press-hardened steel. Welding Journal 95(5): 147-s to 156-s.

14. Saha, D. C., Biro, E., Gerlich, A. P., and Zhou, Y. N. 2016. Fusion zone microstructure evolution of fiber laser welded presshardened steels. Scripta Materialia 121(8): 18-22. DOI: 10.1016/j.scriptamat.2016.04.032

15. Sun, Q., Di, H.-S., Wang, X.-N., Chen, X.-M., Qi, X.-N., and Li, J.-P. 2018. A study on microstructure and properties of PHS fiber laser welded joints obtained in air atmospheres. Materials 11(7): 1135. DOI: 10.3390/ma11071135

16. Sun, Q., Di, H.-S., Wang, X. N., and Chen, X.-M. 2019. Suppression of $\delta$-ferrite formation on Al-Si coated press-hardened steel during laser welding. Materials Letters 245(6): 106-9. DOI: 10.1016/j.matlet.2019.02.111

17. Yao, Z., Guang, X., Zhengyi, J., Tian, J., Yuan, Q., and Ma, H. 2019. Effects of $\mathrm{Ni}$ and $\mathrm{Cr}$ on cryogenic impact toughness of bainite/martensite multiphase steels. Metals and Materials International 25(5): 1151-60. DOI: 10.1007/s12540-019-00262-x

18. Yoon, T. J., Oh, M.-H., Shin, H.-J., and Kang, C.-Y. 2017. Comparison of microstructure and phase transformation of laserwelded joints in Al-10wt\%Si-coated boron steel before and after hot stamping. Materials Characterization 128 (6): 195-202. DOI: 10.1016/j.matchar.2017.02.007

19. Razmpoosh, M. H., Khan, M. S., Kalashami, A. G., Macwan, A., Biro, E., and Zhou, Y. 2021. Effects of laser beam defocusing on high-strain-rate tensile behavior of press-hardened Zn-coated 22MnB5 steel welds. Optics \& Laser Technology 141: 107116. DOI: 10.1016/j.optlastec.2021.107116

20. Khan, M. S., Enrique, P., Song, G., Faria, M. I. S. T., and Zhou, Y. 2020. Laser-assisted wire cladding using a retrofitted laser welding system. Surface Engineering 1-8. DOI: 10.1080/02670844.2020. 1820266

21. Khan, M. S., Razmpoosh, M. H., Macwan, A., Biro, E., and Zhou, Y. 2021. Optimizing weld morphology and mechanical properties of laser welded Al-Si coated 22MnB5 by surface application of colloidal graphite. Journal of Materials Processing Technology 293: 117093. DOI: 10.1016/j.jmatprotec.2021.117093

MUHAMMAD SHEHRYAR KHAN (shehryar.khan@uwaterloo.ca), ELLIOT BIRO, and YIXIANG ZHOU are with the Centre for Advanced Materials Joining, Department of Mechanical and Mechatronics Engineering, University of Waterloo, Waterloo, Ontario, Canada. ANDREW MACWAN is with ArcelorMittal Global Research, Hamilton, Ontario, Canada. 